\title{
Recovery of magnetite-hematite concentrate from iron ore tailings
}

\author{
Mikhail Khokhulya ${ }^{1,{ }^{*}}$, Alexander Fomin ${ }^{1}$, and Svetlana Alekseeva ${ }^{1}$ \\ ${ }^{1}$ Mining Institute of Kola Science Center of Russian Academy of Sciences, Apatity, 184209, Russia
}

\begin{abstract}
The research is aimed at study of the probable recovery of iron from the tailings of the Olcon mining company located in the north-western Arctic zone of Russia. Material composition of a sample from a tailings dump was analysed. The authors have developed a separation production technology to recover magnetite-hematite concentrate from the tailings. A processing flowsheet includes magnetic separation, milling and gravity concentration methods. The separation technology provides for production of iron ore concentrate with total iron content of $65.9 \%$ and recovers $91.0 \%$ of magnetite and $80.5 \%$ of hematite from the tailings containing $20.4 \%$ of total iron. The proposed technology will increase production of the concentrate at a dressing plant and reduce environmental impact.
\end{abstract}

\section{Introduction}

At present, there is an important problem worldwide in the disposal of waste generated during the mineral production and processing. Tailings dumps occupy huge areas and pollute the environment. However, waste material contains some valuable components that can be used in various industries.

In Russia, mining-induced waste occupies more than 300 thousand hectares of lands. According to various reports, the mass of accumulated waste varies from 40 billion tons to 80 billion tons or more [1]. Despite huge resource potential of mining wastes in Russia, they are used mainly in building industry and amount of recycling does not exceed $10 \%$ of their annual generation. In some cases mining-induced deposits are developed to extract associated valuable components which had not been recovered from ores previously [2].

The recycling of tailings to produce iron ore concentrates has a significant potential. Additional recovery of iron minerals from tailing waste can increase resource base of mining companies and amount of produced concentrate. As material of tailings dump has already been grinded, separation process requires much less energy and can also decrease total costs of concentrate production.

Due to gradual depletion of iron ore reserves, more studies are devoted to tailings processing [3-7]. The results of these works indicate the potential recovery of iron ore concentrates from mining-induced mineral materials using gravity, magnetic and flotation separation methods. Some studies are devoted to the use of waste produced during iron ore processing in the production of ceramics, concrete, bricks, pigments and nano-powders [8-12].
The mineral processing plant of the Olcon JSC, located at the Murmansk region, produces magnetitehematite concentrate. The processing technology includes several magnetic separation stages to produce magnetite concentrate and two jigging stages to produce hematite concentrate from a non-magnetic fraction of magnetic separation [13].

In the initial period of plant operation (since 1955) iron ore tailings were stored in the Southern Bay of Kolozero Lake (figure 1). After the construction of the main tailings dump, this area was used for discharge of separation products in case of plant emergency stops. The amount of accumulated material in the dump was accounted for more than 11 million tons in 1998 [14].

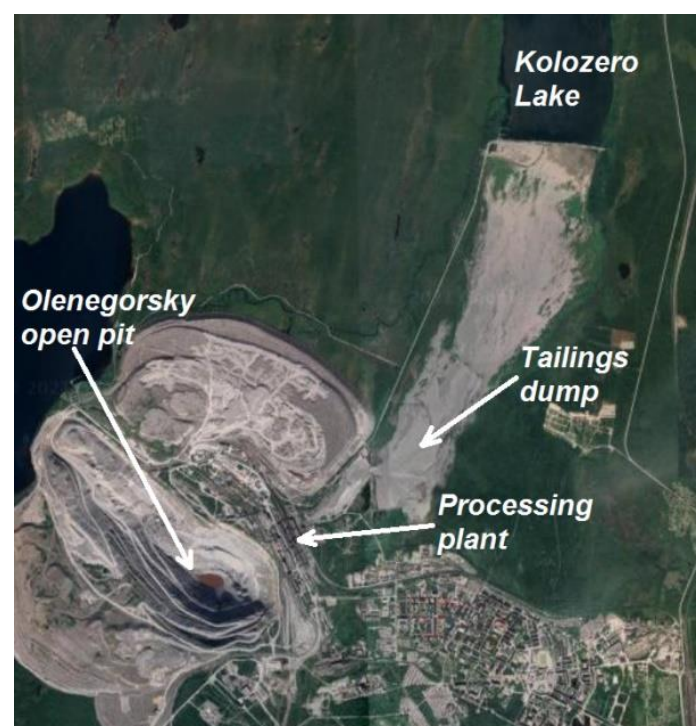

Fig. 1. Satellite images of the tailings dump.

\footnotetext{
* Corresponding author: $\underline{\text { m.hohulya } @, k s c . r u}$
} 
This secondary deposit can be considered as an additional source of raw material because it is located quite close to the plant and its developing won't take a lot of capital expenditures. Also increasing environment impact and the hazard of environmental degradation in the lake requires reduction of dump area and its following liquidation in future.

Thus, we can conclude that the issue of processing of iron ore tailings of the Olcon JSC is an urgent and promising task for both environmental protection and mining industry.

\section{Research object and methods}

A representative sample of the tailings was collected with the use of a dredger. The grain sizes, mineral and chemical compositions of the sample were analysed.

Content of Fe total in tailings is $19.4 \%$, while content of $\mathrm{Fe}$ associated with magnetite and hematite is $10.4 \%$ and $4.9 \%$ respectively.

Grain size analysis (table 1) shows that the yield of size fraction of $-0.63+0.1 \mathrm{~mm}$ is $72.5 \%$. Amount of fine particles with diameter less than $0.071 \mathrm{~mm}$ is about $10 \%$. We can see a tendency of increase of Fe content with grain diameter decrease.

Table 1. The results of grain size and chemical analyses.

\begin{tabular}{|c|c|c|c|c|}
\hline $\begin{array}{c}\text { Grain size } \\
\text { classes, } \\
\text { mm }\end{array}$ & $\begin{array}{c}\text { Yield, } \\
\mathbf{\%}\end{array}$ & $\begin{array}{c}\text { Content } \\
\text { of Fetotal, } \\
\text { \% }\end{array}$ & $\begin{array}{c}\text { Content } \\
\text { of Femag, } \\
\text { \% }\end{array}$ & $\begin{array}{c}\text { Content } \\
\text { of Fehem, } \\
\text { \% }\end{array}$ \\
\hline+1.6 & 3.0 & 7.58 & 2.39 & 1.21 \\
\hline$-1.6+1.0$ & 2.2 & 7.23 & 1.87 & 1.05 \\
\hline$-1.0+0.63$ & 4.2 & 6.82 & 1.46 & 0.73 \\
\hline- & 15.2 & 8.75 & 2.15 & 2.91 \\
\hline $0.63+0.315$ & 27.6 & 12.57 & 4.6 & 4.02 \\
\hline$-0.315+0.2$ & 29.7 & 27.38 & 15.2 & 7.57 \\
\hline$-0.2+0.1$ & 29.9 & 37.44 & 26.67 & 7.6 \\
\hline$-0.1+0.071$ & 7.9 & 27.73 & 19.89 & 4.08 \\
\hline-0.071 & 10.2 & 19.39 & 10.42 & 4.91 \\
\hline Total: & 100.0 & \multicolumn{2}{|c}{} \\
\hline
\end{tabular}

A significant part of total and magnetic iron in the sample is distributed in the size class of $-0.315 \mathrm{~mm}$ $(89.7 \%$ and $95.2 \%$, respectively). Hematite iron is concentrated in the size class of $-0.315+0.071 \mathrm{~mm}$ with $80.6 \%$ distribution as shown in figure 2 . Fe distribution in size classes also shows that we can classify the tailings and process only $-1 \mathrm{~mm}$ or $-0.63 \mathrm{~mm}$ material. This technological solution will allow us to increase $\mathrm{Fe}$ content in the feed of a processing flowsheet. Losses of magnetite and hematite with oversize product will be less than $2 \%$.

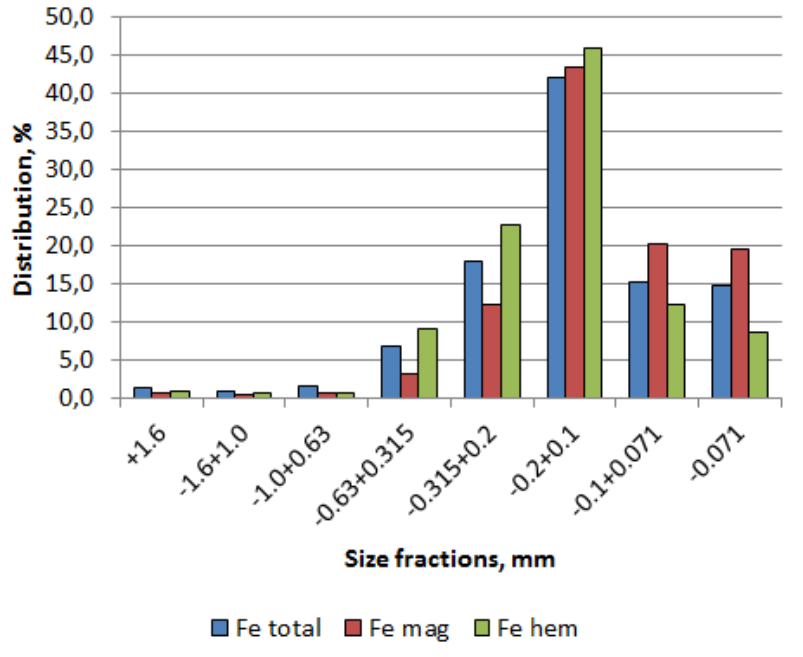

Fig. 2. Fe distribution in size fractions.

According to the results of $x$-ray phase analysis most part of the material is presented by quartz (42.4\%) and feldspar (14.6\%); valuable minerals were identified as magnetite $(14.0 \%)$ and hematite $(7.8 \%)$ as shown in figure 3 . The group of amphiboles includes tremolite, actinolite, cummingtonite, grunerite and hornblende minerals. The series of pyroxenes includes diopside, hedenbergite, aegirine, and augite. Micas were identified as annite, phlogopite and muscovite. Other minor minerals with total content of about $1 \%$ are garnets, epidote, pyrite, pyrrhotite, apatite, and calcite.

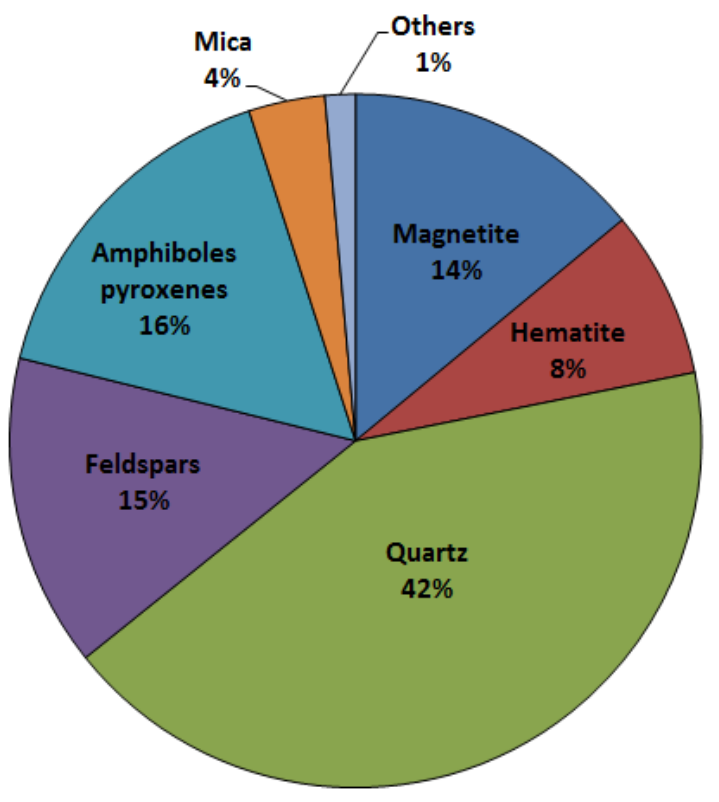

Fig. 3. Mineral composition of the tailings.

Investigation of mineralogical features of the sample has showed that $70 \%$ of magnetite is liberated and for hematite this value is about $90 \%$. In size fraction less than $0.071 \mathrm{~mm} 95 \%$ of magnetite is liberated and such degree of liberation for hematite is achieved in size fraction less than $0.3 \mathrm{~mm}$. Most part of magnetite and hematite with diameter greater than $1 \mathrm{~mm}$ are aggregates 
with waste rock minerals. Valuable minerals liberation data is shown in figure 4 as histograms.

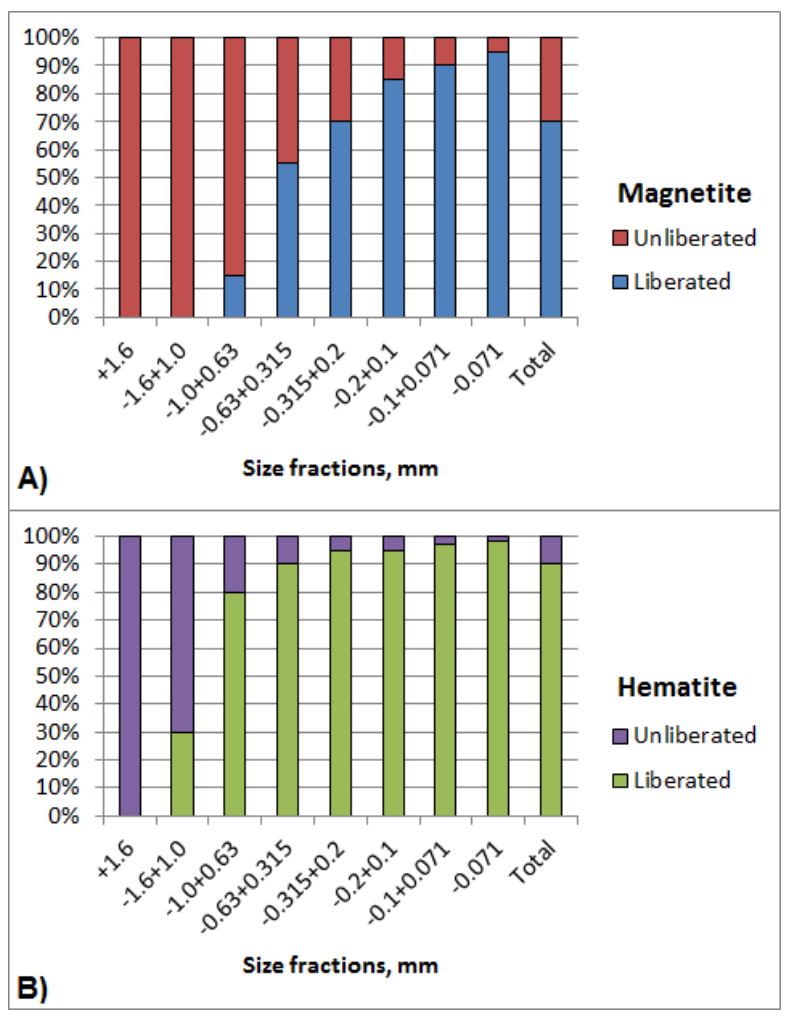

Fig. 4. Liberation of magnetite (A) and hematite (B).

So, revealed features of material composition of the sample create suitable conditions for the use of magnetic separation in low intensity field for magnetite recovery and gravity concentration for hematite recovery.

\section{Results and discussion}

As it was shown above, the tailings contain about $5 \%$ of coarse particles with diameter more than $1 \mathrm{~mm}$. Due to low iron content and big amount of unliberated magnetite and hematite in this fraction, initial tailings were classified using the vibrating screen to remove +1 $\mathrm{mm}$ product from the separation process. Fe total content in undersize product increased to $20.4 \%$.

To recover magnetite from tailings we used magnetic separation. Magnetic fraction contained $59.3 \%$ of $\mathrm{Fe}$ total and recovered $89 \%$ of Fe mag (table 2).

Table 2. The results of the first stage of magnetic separation.

\begin{tabular}{|c|c|c|c|c|c|c|c|}
\hline & \multirow{2}{*}{$\begin{array}{c}\text { Produc } \\
\mathbf{t}\end{array}$} & \multirow{2}{*}{$\begin{array}{c}\text { Yield, } \\
\%\end{array}$} & \multicolumn{3}{|c|}{ Fe content, \% } & \multicolumn{3}{c|}{ Fe recovery, \% } \\
\cline { 3 - 8 } & & Tot & Mag & Hem & Tot & Mag & Hem \\
\hline $\begin{array}{c}\text { Magne- } \\
\text { tic }\end{array}$ & 18.0 & 59.3 & 55.5 & 2.4 & 52.5 & 89.0 & 8.2 \\
\hline $\begin{array}{c}\text { Non- } \\
\text { magne- } \\
\text { tic }\end{array}$ & 82.0 & 11.8 & 1.5 & 5.9 & 47.5 & 11.0 & 91.8 \\
\hline Total & 100 & 20.4 & 11.2 & 5.3 & 100 & 100 & 100 \\
\hline
\end{tabular}

Production of high quality magnetite concentrate from this product is difficult without additional milling because it contains unliberated magnetite [15]. We have investigated liberation of magnetite in a magnetic fraction and proposed additional milling to a size less than $0.1 \mathrm{~mm}$ on the base of the study results. It was established that content of $-0.071 \mathrm{~mm}$ fraction in milled product should be more than $50 \%$ to produce magnetite concentrate with $\mathrm{Fe}$ total content of about $68 \%$ (figure 5).

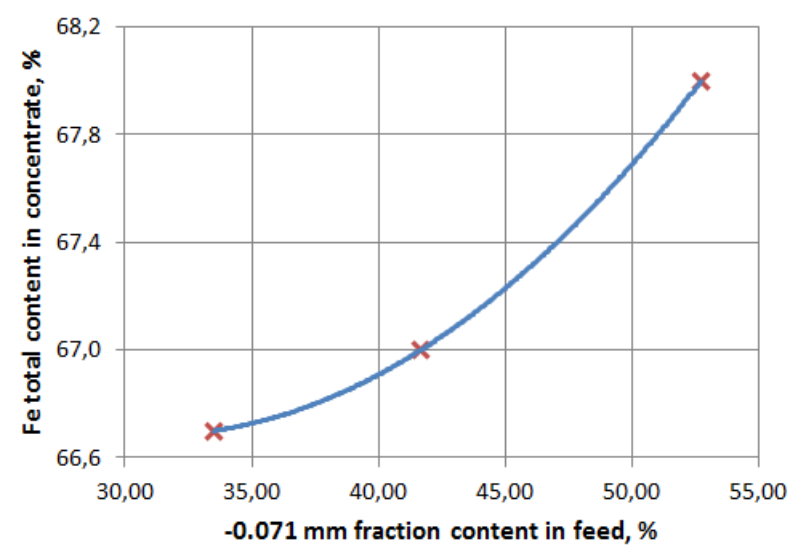

Fig. 5. Dependence of $-0.071 \mathrm{~mm}$ fraction content in the feed of second stage of magnetic separation on concentrate quality.

So, combination of two stages of magnetic separation and milling allowed us to produce magnetite concentrate with $\mathrm{Fe}$ total content of $68 \%$ and $\mathrm{Fe}$ mag recovery of $86.7 \%$.

Nonmagnetic fraction of the first stage of magnetic separation is characterized by Fe total content of about $12 \%$ where most part of iron is concentrated in form of hematite. This product was processed by means of gravity separation methods which are widely used for concentration of hematite ores [16-18]. Gravity concentration does not require significant energy consumption and the use of reagents unlike flotation.

One of the gravity methods is spiral separation. It is high-capacity, low-cost and environmentally friendly method of mineral processing. Spiral concentration is based on separation of mineral particles by their density in a thin centrifugal flow of suspension. Dense hematite particles slide toward the inner part of the spiral surface, where they are recovered as a concentrate by splitters (figure 6). Lighter quartz particles are pushed with water toward the periphery or outer trough of the spiral [17].

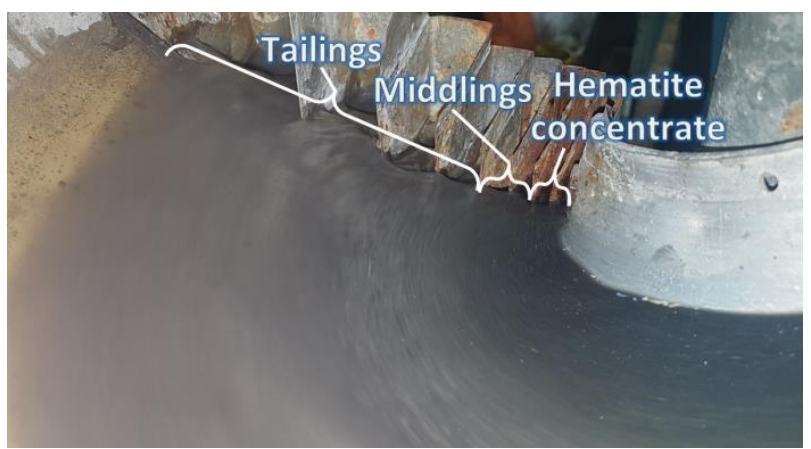

Fig. 6. Particles distribution on spiral surface. 
Two stages of spiral separation allowed us to recover rough hematite concentrate with $\mathrm{Fe}$ total content of $54.5 \%$ and hematite recovery of $73.6 \%$. Further concentration using shaking table increased quality of hematite concentrate to $62.2 \%$ of Fe total.

Separation of spirals middlings did not result in acceptable indicators. Mineralogical investigation showed that about $20 \%$ of hematite in the middlings is unliberated. This fact did not allow us to obtain high quality concentrate during middlings concentration. So we introduced milling of this product into the flowsheet. Milled material with diameter less than $0.2 \mathrm{~mm}$ was processed with spirals and the shaking table. This technological solution increased hematite recovery up to $9 \%$.

On the basis of conducted technological experiments we developed a separation technology. The processing flowsheet is shown in figure 7 .

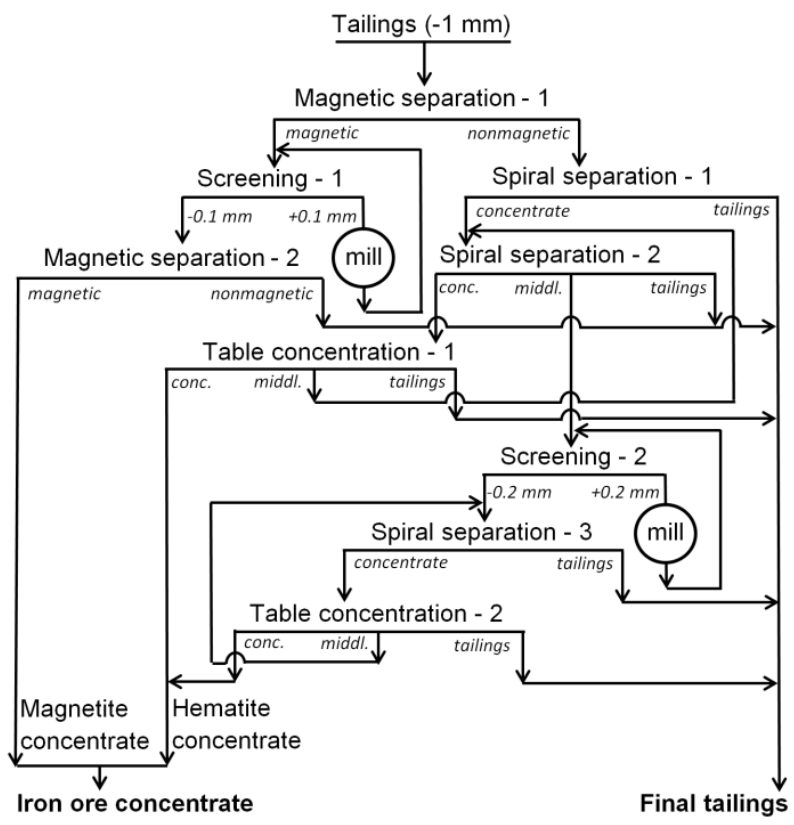

Fig. 7. Flowsheet of developed technology.

Table 3 presents indicators of tailings separation obtained with the use of the developed technology.

Table 3. The results of tailings separation.

\begin{tabular}{|c|c|c|c|c|c|c|c|}
\hline \multirow{2}{*}{ Product } & \multirow{2}{*}{$\begin{array}{c}\text { Yield, } \\
\%\end{array}$} & \multicolumn{3}{|c|}{ Fe content, $\%$} & \multicolumn{3}{|c|}{ Fe recovery, \% } \\
\hline & & Tot & Mag & Hem & Tot & Mag & Hem \\
\hline $\begin{array}{c}\text { Concen- } \\
\text { trate }\end{array}$ & 23.6 & 65.9 & 43.3 & 18.0 & 76.5 & 91.0 & 80.5 \\
\hline Tailings & $\overline{76.4}$ & 6.3 & 3 & 1.4 & 23.5 & 9.0 & 19.5 \\
\hline Feed & 100 & 20.4 & 11.2 & 5.3 & 100 & 100 & 100 \\
\hline
\end{tabular}

Produced concentrate consists of magnetite concentrate ( $\mathrm{Fe}$ total content $-68.0 \%$ ) and hematite concentrate ( $\mathrm{Fe}$ total content $-62.2 \%$ ) so collective concentrate contains $65.9 \%$ of Fe total. Recovery of Fe total in magnetite concentrate is $50.5 \%$ and for hematite concentrate $\mathrm{Fe}$ total recovery is $26 \%$. Mixture of two concentrates gives $76.5 \%$ recovery of Fe total. Most part of magnetite $(86.7 \%)$ was recovered during magnetic separation. $73.9 \%$ of hematite was recovered by gravity concentration. Due to presence of mineral particles in form of magnetite-hematite aggregates, a small amount of hematite is observed in magnetite concentrate and vice versa.

According to obtained results we can conclude that the proposed technology provide for production of magnetite and hematite concentrates with quality corresponding to the quality of concentrates produced at the mineral processing plant of Olcon JSC. Achieved values of iron recovery confirm efficiency of separation.

Despite the high qualitative indicators achieved during the processing of the tailings, the developed technology is characterized by relatively high operating costs for its implementation due to the use of an energyintensive grinding process. Therefore the subject of future research will be optimization of the processing flowsheet in order to reduce operating costs with possible mills exclusion.

\section{Conclusion}

1. Investigation of material composition of the tailing sample has showed that the main valuable minerals in this material are magnetite with $14 \%$ content and hematite with $7.8 \%$ content. Fe total content in the sample is $19.4 \%$.

2. Two stages of magnetic separation with milling of the magnetic product of the first stage to a particle size of less than $0.1 \mathrm{~mm}$ provide for magnetite concentrate with $\mathrm{Fe}$ total content of $68 \%$ and $\mathrm{Fe}$ mag recovery of about $87 \%$.

3. Gravity concentration based on the use of spiral separators and shaking tables makes it possible to produce hematite concentrate with $62 \%$ of $\mathrm{Fe}$ total and Fe hem recovery of about $74 \%$.

4. The developed magnetic-gravity technology for processing of the tailing dump material ensures the production of iron ore concentrate with the total iron content of $65.9 \%$ and recovery of magnetite and hematite of about $91 \%$ and $81 \%$ respectively.

5. Iron recovery from the tailings dump allows decreasing the mass of stored material by $23.6 \%$ and improving an environmental situation in the area.

\section{References}

1. V.V. Karagashev, B.S. Uzhkenov, Technogenic raw-material resources (VIEMS, Kazakhstan, 2003) (in Russian)

2. S.M. Popov, V.A. Kharchenko, Methodological grounds of economical estimation of wastes in mining industry, Gornyi Zhurnal, 1, 86-87 (2009) (in Russian)

3. P.D. Dauce, G.B. de Castro, M.M.F. Lima, R.M.F Lima, Characterisation and magnetic concentration of an iron ore tailings, JMR\&T, 8 , 1052-1059 (2019)

4. K. Hanumantha Rao, K.S. Narasimhan, Selective flocculation applied to Barsuan iron ore tailings, Int. J. Miner. Process., 14, 67-75 (1985) 
5. Y. Wang, J. Ren, The flotation of quartz from iron minerals with a combined quaternary ammonium salt, Int. J. Miner. Process., 77, 116$122(2005)$

6. S. Song, S. Lu, A. Lopez-Valdivieso, Magnetic separation of hematite and limonite fines as hydrophobic flocs from iron ores, Miner. Eng., 15, 415-422 (2002)

7. C. Li, H. Suna, J. Baic, L. Li, Innovative methodology for comprehensive utilization of iron ore tailings, Part 1, The recovery of iron from iron ore tailings using magnetic separation after magnetizing roasting, J. Hazard. Mater., 174, $71-77$ (2010)

8. W.C. Fontes, J.M. Franco de Carvalho, et all, Assessment of the use potential of iron ore tailings in the manufacture of ceramic tiles: From tailings-dams to "brown porcelain", Constr. Build. Mater., 206, 111-121 (2019)

9. C. Tang, K. Li, W. Ni, D. Fan, Recovering iron from iron ore tailings and preparing concrete composite admixtures, Minerals, 9, 2-14 (2019)

10. L. Weishi, L. Guoyuan, X. Ya, The properties and formation mechanisms of eco-friendly brick building materials fabricated from low-silicon iron ore tailings, J. Clean. Prod, 204, 685-692 (2018)

11. B.G.J. Lucas, A.H. Dias, B.G. Jorge, Reuse of iron ore tailings from tailings dams as pigment for sustainable paints J. Clean. Prod., 200, 412-422 (2018)

12. E. Darezereshki, A.K. Darban, M. Abdollahy, Synthesis of magnetite nanoparticles from iron ore tailings using a novel reduction-precipitation method, J. Alloys Compd., 749, 336-343 (2018)

13. A.V. Fomin, M.S. Khokhulya, Improving efficiency of gravity separation of fine iron ore materials using computer modeling, Topical Issues of Rational Use of Natural Resources, 2, 509-516 (2020)

14. V.A. Lotsmanov, A.N. Dmitrienko T.M. Kiseleva, A.U. Markov, Experience of concentration of tailings from processing plant of Olenegorsky GOK, Russian Mining Industry, 3, 42-45, (2003) In Russian

15. M.A. Bikbov, V.V. Karmazin, A.A. Bikbov, Low-intensity magnetic separation: principal stages of a separator development - what is the next step?, Physical Separation in Science and Engineering, 13, 53-67 (2004)

16. B.Y. Cui, D.Z. Wei, R.Y. Zhang, S.Y. Zhang, Research on improving the classification-gravity concentration technology based on an Anshantype low-grade hematite ore, Adv. Mat. Res., 454, 256-260 (2012)

17. C. Bazin, M. Sadeghi, P. Roy et all, Size recovery curves of minerals in industrial spirals for processing iron oxide ores, Miner. Eng., 65, 115123 (2014)

18. S. liu, Y. Zhao, W. Wang, S. Wen, Benefication of a low-grade hematite-magnetite ore in China, Miner. Metall. Proc., 31, 136-142 (2014). 